\title{
Memoria, verdad y justicia en el territorio 11. Desafíos en la politización del exilio colombiano
}

\author{
Memory, Truth and Justice in Territory 11. Challenges in the \\ politicization of Colombian exile \\ Memória, Verdade e Justiça no Território 11. Desafios na politização do \\ exílio colombiano \\ Diana ORTIZ, Argentina \\ MECoPa, doctoranda IDES/UNGS / dportiz.c@gmail.com \\ Carlos SALAMANCA, Argentina \\ Universidad de Buenos Aires, Argentina / salamanca.carlos@gmail.com \\ Verónica TORRAS, Argentina \\ Asociación Civil Memoria Abierta / mvtorras@gmail.com
}

Chasqui. Revista Latinoamericana de Comunicación

N. ${ }^{\circ} 143$, Abril-Julio 2020 (Sección Monográfico, pp. 81-96)

ISSN 1390-1079 / e-ISSN 1390-924X

Ecuador: CIESPAL

Recibido: 22-12-2019/Aprobado: 12-O3-202O 


\section{Resumen}

La Comisión de la Verdad abrió la puerta al reconocimiento de miles de víctimas del exilio en el contexto del conflicto armado colombiano. La incorporación del exilio como hecho victimizante reconoce no sólo su dimensión, profundidad y alcance sino también las trayectorias organizativas y la agencia política de quienes se vieron forzados a salir del país. Describimos aquí algunas experiencias latinoamericanas previas extra-territoriales de lucha por memoria, verdad y justicia oficiales y no-oficiales. Analizamos luego la trayectoria del colectivo de exiliados/as MECoPa, y sus desafíos. Concluimos analizando ese campo que si bien no se limita al aparato de la justicia transicional colombiana, encuentra allí una oportunidad única de politización de la experiencia del exilio.

Palabras clave: exilio, justicia transicional, Colombia, derechos humanos

\section{Abstract}

The Colombian National Truth Commission opened the door to the recognition of thousands of victims of exile in the context of the "armed conflict". The incorporation of exile as a victimizing act recognizes not only its dimension, depth and scope, but also the organizational trajectories and the political agency of the victims who forcibly left the country. In this contribution, we describe some previous extra-territorial Latin American, official and unofficial experiences of struggle for memory, truth and justice. We then analyze the trajectory of MECoPa, one specific group of victims, and its challenges. We conclude by analyzing this field, which, although it is not limited to the Colombian transitional justice apparatus, finds there a unique opportunity to politicize the exile experience.

Keywords: exile, transitional justice, Colombia, human rights

\section{Resumo}

A Comissão da Verdade da Colômbia abriu as portas para o reconhecimento de milhares de vítimas de exílio no contexto do conflito armado colombiano. A incorporação do exílio como ato vitimizador reconhece não apenas sua dimensão, profundidade e abrangência, mais também as trajetórias organizacionais e a agência política das vítimas que deixaram o país à força. Descrevemos aqui algumas experiências latino-americanas extraterritoriais anteriores de luta pela memória, verdade e justiça oficiais e não oficiais. Em seguida, analisamos a trajetória do coletivo de vítimas MECoPa e seus desafios. Concluímos analisando esse campo que, embora não se limite ao aparato de justiça transicional colombiano, encontra uma oportunidade única de politizar a experiência do exílio.

Palavras-chave: exílio, justiça de transição, Colômbia, direitos humanos 


\section{Introducción}

A pesar de sus apariencias, la construcción de los procesos de memoria, verdad y justicia están lejos de restringirse a los marcos nacionales y, como lo afirmó Beristain en una entrevista reciente (2019), las lecciones aprendidas en procesos de paz en algunos países alimentan nuevas experiencias en otros. Los vasos comunicantes entre esas experiencias son fluidos y activos de tal manera que los procesos en países como Guatemala, México, Colombia, Argentina o Chile son el resultado de una red vital de actores que, a distintas escalas y desde diferentes prácticas, viene trabajando desde hace varias décadas por la memoria, la verdad y la justicia.

A finales del 2020, se instalaron en la ciudad de Buenos Aires, tres marcas territoriales de la memoria en homenaje a cinco personas colombianas que fueron detenidas y desaparecidas en Argentina. En un caluroso día soleado se dieron cita integrantes de los Organismos de Derechos Humanos y más de cuarenta delegados de los colectivos de exiliados y refugiados colombianos en once países de la región, miembros de la Red de Víctimas Colombianas por la Paz en Latinoamérica y el Caribe (REVICPAZ-LAC).

Ese fue uno de los momentos más visibles de un trabajo de muchos años en favor de un territorio de elocución, visibilidad y justicia para miles de colombianos en el exilio. También fue la expresión de un sincretismo entre formas de hacer memoria que permitió poner en diálogo el pasado militante de un grupo de colombianos en la Argentina en los años setenta, con el esfuerzo de las organizaciones de colombianos y colombianas que luchan por construir hoy verdad sobre el conflicto en su país. El trabajo de memoria se propone al mismo tiempo recuperar los procesos sociales y políticos de transformación, comprender las dinámicas de las violencias que los desarticularon y organizarse para resistir: esto atraviesa transversalmente los diferentes procesos y permite conectarlos y enriquecerlos.

A través del análisis histórico-documental de algunas experiencias latinoamericanas de personas y comunidades desde el exilio, en esta contribución nos proponemos esbozar los principales desafíos a los que se enfrentan los colectivos de víctimas frente al reconocimiento del exilio como hecho victimizante. Haciendo alusión a las diez jurisdicciones que se establecieron en el territorio colombiano para llevar a cabo las políticas de memoria, verdad y justicia, el territorio once sería el espacio desde donde se impulsa una agenda de derechos humanos para las personas en el exilio; en este sentido, este trabajo es una cartografía de ese territorio en formación.

A través de una revisión bibliográfica, en la primera parte, repasamos algunas experiencias extra-territoriales de lucha por memoria, verdad y justicia en América Latina con el fin de analizar en qué términos ha venido siendo planteada la experiencia del exilio en el marco de los procesos transicionales y la manera en que unas y otras experiencia se han retroalimentado mutuamente. En la 
segunda parte, nos centramos en el proceso de sistematización de experiencias que viene adelantando una agrupación colombiana de víctimas en Argentina, en donde destacamos el proceso por el cual el exilio fue problematizado como un hecho victimizante. En la tercera parte, analizamos las derivaciones que pueden extraerse a partir de pensar en términos políticos el exilio y el exiliado como sujeto político. La Comisión para el Esclarecimiento de la Verdad, definió su despliegue a partir de la constitución de once espacios territoriales, el territorio 11 corresponde al internacional. Los seis elementos que proponemos aquí nos conducirán a esbozar algunos de los retos y los desafíos que presenta imaginar y habitar el territorio 11 como lugar de elocución por la memoria, la verdad y la justicia de la población colombiana en el exilio.

\section{Algunas experiencias extra-territoriales de lucha por memoria, verdad y justicia en América Latina}

El trabajo que varias organizaciones de colombianos/as en el exilio vienen desarrollando para que el exilio sea leído e interpretado con una perspectiva de derechos humanos se apoya sobre una rica base de experiencias extraterritoriales de lucha por la memoria, la verdad y la justicia en América Latina. En este apartado hacemos un repaso no exhaustivo por algunas de esas experiencias, sus lecciones y aprendizajes, que consideramos pueden ser de interés para pensar el reconocimiento de los exiliados como sujetos políticos. Abordamos el caso de Guatemala, las experiencias de latinoamericanos en Europa y de muchos ciudadanos bolivianos y paraguayos que migraron a la Argentina. Posteriormente nos detenemos en el caso de El Salvador pues consideramos que los desafíos a los que se enfrentan las organizaciones de colombianos/as en el exilio pueden encontrar allí referencias importantes.

El gran éxodo de comunidades indígenas desde Guatemala hacia el sureste mexicano se produce en 1978 con el pico más alto de la represión y las políticas genocidas durante los gobiernos de Lucas García y Ríos-Montt (1982-1983). Los exiliados encuentran en Méxicouna red de apoyoya constituida deguatemaltecos exiliados en décadas anteriores. Entre ese universo se distinguen, de acuerdo a Ludec (2001, p.4), los 'asilados' (individuos perseguidos individualmente) y los 'refugiados' (miembros de una comunidad, en particular indígenas del campo y ciudadanos de diferentes sectores de la sociedad civil que huyen una situación de guerra civil y genocidio).

Fiel a su tradición, el Estado mexicano tomó medidas a favor de esos migrantes con políticas de reconocimiento, tierras y ciudadanía. En el exilio, algunos guatemaltecos se articularon a organizaciones insurgentes y surgieron experiencias asociativas de diverso tipo, como la Iglesia Guatemalteca en el Exilio que surge tras la persecución y represión desatada contra los miembros de la Diócesis del Quiché, y que tuvo un papel fundamental para los refugiados. 
Las investigaciones realizadas en ese periodo muestran cómo la incertidumbre, la duda y la nostalgia coexistían con un importante compromiso con el regreso a Guatemala y el movimiento revolucionario. A finales de los años ochenta se dieron algunas reuniones gubernamentales en el marco de los Acuerdos de Paz. Entre ellas se destaca el Diálogo Nacional que contó con la participación inédita de grupos representativos del exilio, y de refugiados campesinos e indígenas que viajaron desde México a Guatemala. Sobre la base de una alianza consolidada con la cooperación de instituciones mexicanas, organizaciones internacionales y organismos multilaterales como ACNUR y una activa agencia por parte de las víctimas, se produjo el regreso masivo a Guatemala en 1992 y 1993. Asimismo, la Comisión para el Esclarecimiento Histórico de Guatemala recogió testimonios de forma directa en México, mientras que en los demás casos lo hizo por intermedio de ONG. En marzo de 2020 se cumplieron 40 años del exilio guatemalteco y la fecha tuvo conmemoraciones (Lima, 2020), incluso entre las comunidades de refugiados que decidieron permanecer en México y entre quienes la memoria acerca del exilio no ha tenido mayor lugar en el ámbito público. No obstante, allí emergieron algunas iniciativas que pueden contribuir a la elaboración de una narración colectiva de la experiencia del exilio, que ayude a las nuevas generaciones a recuperar su pasado y a sostener un proyecto comunitario con mirada al futuro.

Otro capítulo en las experiencias extra-territoriales aprendidas sobre las luchas por la memoria, verdad y justicia en América Latina lo ocupan las experiencias de latinoamericanos en Europa; con casi cuatro décadas de recorrido, esas experiencias permiten observar fenómenos de larga duración. En este universo complejo y diverso que no es nuestro propósito simplificar, destacamos, primero, que muchos de esos exiliados desarrollaron una importante agenda de derechos humanos por la visibilización de la represión (Jensen, 1998, p. 130). Segundo, que ese trabajo político se situó en el dominio de la representación y de construcción de una verdad distinta a la que difundían los gobiernos autoritarios. Los numerosos intelectuales, artistas y académicos que habían partido al exilio desarrollaron en sus países de llegada un sinnúmero de acciones; algunas se vincularon activamente a erosionar la legitimidad de los gobiernos autoritarios, constituir redes de apoyo y dibujar proyectos y posibilidades del regreso.

Las personas que tuvieron que dejar Uruguay por motivos políticos entre las décadas de los años sesentas y ochentas constituyen una parte significativa de la sociedad. Muchos de ellos eran personas que al haber integrado organizaciones sociales, sindicales, políticas habían adquirido un capital para el desarrollo de redes de apoyo y solidaridad y de denuncia a la dictadura que se extendieron por diferentes países especialmente europeos. Entre otros sobresale el Frente Amplio con redes que traspasaban las barreras nacionales. La firma del Acuerdo Convergencia Democrática (1980) habilitó reflexiones transversales acerca del exilio, una consolidación y visibilidad que crecían al mismo tiempo que el 
gobierno en Montevideo mostraba signos de debilidad hasta su caída en 1985 , que abrió las puertas para el regreso. En el caso de Chile, en donde se dio una política sistemática de exilio y extrañamiento a gran escala hasta casi el fin de la dictadura, el exilio no ha sido problematizado sino recientemente con algunas iniciativas que proponen pensar el exilio no desde una perspectiva de derechos humanos sino desde la perspectiva de la experiencia y la dimensión existencial ${ }^{1}$.

En el caso de Argentina, fueron diversas las organizaciones creadas en el exilio: entre las más activas es posible mencionar a COSPA (Comité de Solidaridad con el Pueblo Argentino), CALPA (Comité de Ayuda del Pueblo Argentino), CADHU (Comisión Argentina de Derechos Humanos), OSEA (Oficina de Solidaridad con el exilio argentino), algunas de ellas funcionaron con apoyo de organizaciones políticas y otras surgieron del activismo en derechos humanos. Los primeros testimonios de exiliadas y exiliados que denunciaban la existencia de centros clandestinos de detención y las dinámicas represivas fueron recibidos y hechos públicos por estas organizaciones en plena dictadura. Fue también desde estas organizaciones que comenzó a vislumbrarse y plantearse la posibilidad de un horizonte de justicia para el caso argentino.

No obstante, en muchos países del Cono Sur, el retorno de los exiliados se dio en medio de disputas de sentido sobre las razones de su partida. En Argentina por ejemplo, los exiliados encontraron que ideas como las de los "exilios dorados" -promovidas por el gobierno militar-, estaban vigentes y eran reproducidas por un sector importante de la sociedad. Como afirma Jensen, se trataba de enfrentar una verdadera "estigmatización social y política" (2017, p. 5).

Un tercer universo de exilio lo constituyen las experiencias de muchos ciudadanos bolivianos y paraguayos que migraron a la Argentina como resultado de las políticas represivas de gobiernos autoritarios que se produjeron en la década de los años 70. Allí algunos de ellos participaron de organizaciones sociales e incluso de movimientos armados que, a lo largo de los años, se fueron manifestando como articuladas en trayectorias que suturaban los mundos que habían sido disociados por cuenta del exilioº ${ }^{2}$. En lo que tiene que ver con las violaciones de derechos humanos y los ciudadanos en el exilio, la Comisión Verdad y Justicia de Paraguay celebró dos audiencias en Argentina; una en el Congreso de la Nación en la ciudad de Buenos Aires y otra en la ciudad fronteriza de Posadas (Misiones).

Sintetizando el trabajo de recolección de testimonios en el exilio, a las experiencias ya citadas de Guatemala y Paraguay, hay que añadir que hubo comisiones que, aunque no apostaron por hacer un reconocimiento expreso del fenómeno como un hecho victimizante en sí mismo, sí identificaron su manifestación como consecuencia de otros hechos de la misma naturaleza (CNMH, 2018, p. 310). Las comisiones de Ecuador y Guatemala recibieron declaraciones en los países identificados como los principales territorios de

1 Entre otras, ver Exilio chileno. Recuperado de: http://chile.exilio.free.fr/index.htm

2 Ibid. 36. 
acogida de la población exiliada (CNMH, 2018. p. 390). La Comisión de Chile señaló que se convocó a familiares de víctimas a inscribir sus casos y solicitar audiencia ante la Comisión; en este caso, el registro y las solicitudes de quienes se encontraran en el exterior, se hizo en las embajadas y consulados (CNMH, 2018, p.392). En el caso argentino la CONADEP (Comisión Nacional sobre la Desaparición de Personas) logró que se habilitaran las embajadas y consulados argentinos en el extranjero para que la población exiliada formulara allí sus denuncias o aportara sus testimonios, siempre y cuando se refiriera a casos de desaparecidos (CNMH, 2018, p. 393). Integrantes de la CONADEP realizaron viajes a distintos países de América y Europa para recibir material probatorio, mientras que su presidente mantuvo más de 100 entrevistas personales, radiales y televisivas dentro y fuera del país.

Pero otro espejo en que es pertinente pensar la reflexión sobre el exilio colombiano lo constituye El Salvador, un país del que miles de personas migraron a Estados Unidos en el contexto de las políticas de guerra fría y los gobiernos contrainsurgentes apoyados por Estados Unidos. Lo que se produjo no fue un proceso migratorio homogéneo y en bloque hacia ese país y más bien existieron numerosas trayectorias previas que combinaron la autoprotección en campos de refugiados y enrolamiento en movimientos insurgentes inscritos en las plataformas políticas salvadoreñas (Silber, 2012, p. 128). Una vez en Estados Unidos, los migrantes salvadoreños, principalmente en Los Ángeles, empezaron a organizarse, crecer y multiplicarse bajo una identidad salvadoreña imaginada como opuesta a la de otros inmigrantes con quienes mantenían relaciones de hostilidad (Zúñiga Núñez, 2010, p. 65). Esas organizaciones se fueron consolidando y degradando hasta constituir las maras, redes delictivas internacionales dedicada a un sinnúmero de actividades ilegales. Al igual que en muchos otros casos, las iniciativas desde el exilio se centraron en la denuncia del régimen militar y el apoyo estadounidense a la guerra. Como consecuencia de las políticas migratorias estadounidenses, los jóvenes integrantes de las maras fueron expulsados compulsivamente a sus países "de origen". Puesto que muchas veces El Salvador era el país de origen de sus padres y por lo tanto era un país desconocido para esos jóvenes, se generaba un paradójico doble extrañamiento en estos jóvenes doblemente inmigrantes. Al regresar, sin otras redes de apoyo ni vínculos sólidos de pertenencia, "los mareros" creciendo hasta alcanzar números significativos, elevando exponencialmente sus territorios de influencia y sus niveles de violencia. Durante la transición política en El Salvador y en los años siguientes, el campo de la memoria se ha caracterizado por disputas, en la construcción de la memoria histórica entre las principales fuerzas políticas (Sprenkles, 2012, p. 72). Pero para muchos jóvenes cuyas trayectorias de vida tejen los paisajes de múltiples violencias en los campos salvadoreños y las inner cities norteamericanas, esas memorias no parecieron ofrecer territorios donde fuese posible construir sentido y dar significación a la experiencia del exilio. Por otro lado, para muchos salvadoreños que lucharon 
por un país mejor y tuvieron que huir al exilio, el regreso implicó no solamente confrontarse con un país en acelerada transformación sino articularse a un territorio en el que las dificultades tanto personales como colectivas a veces cubren de desesperanza los proyectos políticos de transformación social. Para muchos colombianos en el exilio que habitan diversos paisajes de precariedad, las políticas institucionales de memoria, verdad y justicia corren el riesgo de resultarles inalcanzables.

A pesar de la enorme diversidad de experiencias que presentamos aquí hay características que son transversales y comunes. Las experiencias de las luchas por la memoria, verdad y justicia de los países en postconflicto en toda América Latina son simultáneas al remonte del proyecto neoliberal (Silber, 2012, p. 131) lo que significa la reducción del Estado, la desregulación del mercado laboral, el confinamiento de la memoria sobre el pasado reciente como algo que pertenece al pasado y, en años más recientes, un endurecimiento de las políticas migratorias. Incluso en países como Argentina, el paradigma de memoria, verdad y justicia que parecía haber sido incorporado por toda la sociedad fue puesto en cuestión en años recientes. En el contexto de las décadas de los años 1990 y 2000, la problematización de la experiencia del exilio como una violación de derechos humanos no encontró un lugar donde acogerse salvo algunas excepciones que ya se han señalado como las de Paraguay, donde se establecieron mecanismos de recolección de testimonios o las de Guatemala, donde se impulsaron políticas de retorno colectivo.

Vista en términos generales, la práctica del exilio lejos de ser excepcional, es una forma de violencia presente a lo largo de toda la trayectoria regional y común a todos los países latinoamericanos y en este sentido, es constitutiva de la política, no ajena a ella. El exilio ha sido tradicionalmente visto en relación a la experiencia existencial y por lo tanto, ha dado lugar a situaciones consolidadas de impunidad para cientos y miles de personas que en el país de origen o de destino, habitan un intersticio en el que su experiencia no puede ser representada ni tramitada como una experiencia de violación de derechos humanos.

La posibilidad de que el esclarecimiento de la verdad se convierta en poderoso elemento de construcción de sentido y movilización social depende también del grado de reconocimiento que el Estado y la comunidad nacional e internacional realicen de los sujetos políticos. Como veremos, la experiencia de los colombianos en el exilio se nutre de las dinámicas sociales de cada país. En Argentina por ejemplo, de los debates por memoria, verdad yjusticia quellegaron a constituir un paradigma social, presente tanto en las huellas materiales de los derechos humanos como en el debate público en el que proyectos políticos como el del feminismo se alimentan de ese paradigma.

Para los y las colombianos en el exilio resulta fundamental encontrar la manera en que sus voces puedan ser escuchadas y que sus testimonios se inscriban en un campo político de reconocimiento de derechos. Es a través de 
esto que los exiliados darán pasos más firmes en su constitución como sujetos políticos y podrán aportar a los procesos de construcción de paz en el territorio nacional. Al respecto Beristain subraya que diferentes organizaciones han manifestado desde el exilio su deseo de "contribuir a la implementación en los mecanismos para la terminación del conflicto y la construcción de una paz estable y duradera" (sf.: 14).

Como se señala en el documento de CNMH y como veremos en el siguiente apartado, organizaciones colombianas en el exilio vienen elevando sus demandas ante el Estado colombiano para que reconozca el exilio como una forma de violencia del conflicto armado, la violencia y la persecución (CNMH, 2018, p. 290) y en dicha línea han puesto en marcha procesos autónomos de reconstrucción de sus memorias, individuales y colectivas (CNMH, 2018).

\section{El exilio colombiano. La experiencia de MECoPa}

Los procesos extraterritoriales contienen de manera significativa, por lo menos en los casos de América Latina, la denuncia de graves violaciones a los derechos humanos y campañas de solidaridad para con los países con conflictos armados internos y dictaduras cívico-militares.

La colectividad colombiana en diversas latitudes del mundo ha impulsado distintas y nutridas iniciativas en esa línea entre las que se destaca el activismo promovido y desarrollado desde Europa, por su duración, impacto e incidencia. Estas agendas en el exterior hasta el siglo pasado respondieron fundamentalmente a las demandas y plataformas o agendas internacionales de las organizaciones sociales y movimientos políticos colombianos, sin reivindicaciones propias frente a la condición misma del exilio.

El siglo XXI trajo algunos cambios en estas dinámicas. La implementación del Plan Colombia tras la ruptura de los diálogos de paz (1999-2002), registró un significativo incremento del desplazamiento forzado interno y transfronterizo, principalmente de población rural. A mediados de la primera década de este siglo e inicios de la segunda, la persecución política a gran escala contra defensores de derechos humanos, intelectuales, líderes sociales y políticos, se sumó al desplazamiento forzado interno.

Rápidamente la población colombiana pasó a ser la principal peticionante de asilo y refugio en la región de América Latina. Para la segunda mitad de la primera década la Oficina del Alto Comisionados de las Naciones Unidas para los refugiados (ACNUR) registró 193.074 personas de origen colombiano con necesidades de protección internacional en países América Latina y el Caribe, el 70\% de ellas se encontraban en Ecuador.

Durante la segunda década del siglo empiezan a emerger espacios de encuentro de colombianos y colombianas en países de América Latina, análogos a las experiencias en Europa, que se suman a las acciones de denuncia, pedidos 
de solidaridad y a la promoción a nivel internacional de las plataformas de los movimiento sociales y políticos de Colombia.

Entre la gran diversidad del universo del exilio forzado colombiano, es posible destacar hoy tres categorías: (i) Exiliados/as políticos/as (personas que sufrieron persecución directa a causa de sus actividades políticas, comunitarias o humanitarias; (ii) Desplazados/as forzados/as transnacionales (personas que se vieron obligadas a salir del país en el marco de acciones militares dirigidas al control territorial); y (iii) Víctimas del conflicto sin acceso a protección y reparación integral (personas que tras sufrir diversos hechos victimizantes, no lograron reconstruir sus proyectos de vida y deciden migrar fuera del país). Las tres categorías enumeradas cuentan con personas con estatus de refugiadas, peticionantes de asilo y migrantes (Ortiz y Viloria; 2018, p-8-9).

Tres eventos político-jurídicos permiten caracterizar la politización del exilio colombiano actual: la promulgación de la Ley de Víctimas y Restitución de Tierras (Ley 1448/2011); la instalación de los diálogos de paz en La Habana, Cuba (2012) y la posterior firma del Acuerdo Final para la Terminación del Conflicto Armado y la Construcción de una Paz Estable y Duradera (2016). Estos hitos históricos dieron lugar al surgimiento tanto de nuevos marcos políticos y herramientas jurídicas como a nuevas dinámicas organizativas y de movilización transnacional que posibilitaron la construcción de agendas alrededor de demandas propias de refugiados/as, exiliados/as y víctimas del conflicto en el exterior.

En ese contexto y tras un par de años de encuentros de exiliados/as colombianos/as para reflexionar y compartir ideas sobre cómo aportar en la búsqueda de la paz desde Argentina (2011-2013), surgió el colectivo Migrantes y Exiliados/as Colombianos/as por la Paz -MECoPa- (2014) que nuclea principalmente a defensores y defensoras de derechos humanos exiliadas y refugiadas compuesto en un $65 \%$ de mujeres, $29 \%$ de personas LGTBI y el resto de varones, entre los 35 y 50 años. Oriundos de diversas zonas del país y con multiplicidad de experiencias de militancia social y política tanto en Colombia como en Argentina.

El objetivo general del colectivo es promover la participación de las poblaciones con necesidades de protección internacional en el diseño, ejecución, implementación y seguimiento de las políticas públicas referidas a: (i) La búsqueda de soluciones estables y duraderas; (ii) El derecho a la memoria, la verdad y la justicia; (iii) la reparación integral y las garantías de no repetición. Su trabajo se organiza en planes de acción anuales y planes de incidencia quinquenales. Alrededor de estos puntos MECoPa logró presentar propuestas a la Mesa de Diálogos en La Habana, a la par que adelantaba una campaña de difusión y pedagogía con población refugiada en Argentina sobre la Ley de Víctimas y el punto cinco de los diálogos de paz (2015) ${ }^{3}$. Asimismo, en

3 El Acuerdo Final para la Terminación del Conflicto y la Construcción de una Paz Estable y Duradera, amplía el concepto de víctima y reconoce el exilio como un hecho victimizante al establecer el compromiso 
2016 cumplió un activo rol en la campaña por el SI en el plebiscito "La paz si es conmigo”, impulsó la constitución de la Mesa de Víctimas del Conflicto Armado Colombiano en Argentina y dio inicio al proceso de construcción de una red de refugiados/as, exiliados/as y víctimas migradas en países de la región, a partir del cual surgió en el 2017 la Red de Víctimas Colombianas por la Paz en Latinoamérica y el Caribe (REVICPAZ-LAC).

Entre las propuestas presentadas por MECoPa para la implementación del punto cinco en lo referido a exilio y víctimas en el exterior se destacan la propuesta de ajuste normativo a la Ley 1448" (2017), las recomendaciones para los programas de retorno voluntario, digno y con garantías (2018) y los aportes para la implementación del enfoque extraterritorial de la Comisión de la Verdad (2018); acciones sumadas al acompañamiento y asesoría sobre acceso a derechos de víctimas del conflicto colombiano en Argentina.

A lo largo de estos años MECoPa ha ampliado su agenda a temas regionales frente a la emergencia de posiciones negacionistas en materia de memoria, verdad y lajusticia y los retrocesos que en los últimos años se han dado en materia de protección internacional. A una escala más global, el colectivo participó activamente en la discusión del Pacto Global para los Refugiados (2018) y se vinculó a procesos organizativos de población refugiada y peticionante de asilo en diferentes lugares y países de origen del mundo e impulsó la participación de REVICPAZ-LAC en la primera Cumbre Global de Refugiados (2018).

Procesos que dan cuenta de que la agencia no puede ser entendida como un qué o un quién (entidad-agente) sino como un proceso que territorializa la capacidad de y para actuar, y a la vez que cuestiona el contexto en que opera, lo reordena (subvierte-cuestiona y construye-ordena) como afirman Deleuze y Guattari (citados por Ema, 2000).

Por otro lado, la experiencia de MECoPa permite comprender que la emergencia y mantenimiento de redes depende del contexto histórico y político en medio del cual se produce el éxodo y de los capitales sociales y políticos de los que disponen los migrantes; de ello da cuenta el proceso desarrollado por este colectivo del exilio colombiano, el cual no hubiesen sido posibles sin las alianzas construidas con actores relevantes en el contexto local colombiano, argentino y regional. En particular, entendemos que la experiencia argentina en la lucha por la memoria, la verdad y la justicia y la alianza con organizaciones de derechos humanos argentinas han nutrido el proceso de participación e incidencia impulsado por MECoPa.

Pollak (2006, p.24) plantea que los escenarios sociales, políticos y culturales de determinado contexto hacen viables procesos de elaboración narrativa de experiencias que en otro contexto se hallaban obstruidos o censurados. En palabras de Ema "el sujeto no es el antecedente racional, autónomo y

del Estado impulsar un programa de reconocimiento y reparación de víctimas en el exterior, incluyendo refugiados y exiliados victimizados con ocasión del conflicto (Acuerdo Final, 2016: 183) 
transparente de la acción, sino que se crea en ella" (2004, p.11), el sujeto es un agente situado en contextos concretos, estructurados y estructurantes.

En el surgimiento de sujetos-agentes es posible identificar aquellos que trascienden a los Estados-nación como los vinculados a la justicia global o a los derechos humanos, que se enmarcan en el orden transnacional y que en algunas oportunidades se encuentran vinculados a sujetos/as o poblaciones migrantes y refugiadas, como puede ser el caso de la experiencia que se presenta en este trabajo.

\section{Politizar el exilio}

El enfoque extraterritorial de la Comisión para el Esclarecimiento de la Verdad, la Convivencia y la No Repetición, desde donde ha logrado abrir un espacio institucional para el encuentro de personas forzadas al exilio. Desde la instalación de los diálogos de paz en La Habana, se puso sobre la mesa la migración forzada, un primer gran paso para avanzar en el reconocimiento de este fenómeno como parte de las violaciones a los derechos humanos.

Sin duda uno de los grandes retos de la Comisión y de las redes aquí mencionadas será el de politizar el exilio. A la luz de lo reflexionado en este artículo, entendemos que este objetivo implica diversos reconocimientos y acciones.

En primer lugar, implica reconocer que la práctica del exilio, como ya mencionamos, lejos de ser excepcional, es una forma de violencia común y constitutiva de la política de la mayoría de los países de la región, que debe ponerse en diálogo con otras experiencias de destierro y migración. Segundo, la migración forzada ha sido un rasgo permanente a lo largo de la historia colombiana, marcada por la violencia política y aunque el exilio suele asociarse a regímenes dictatoriales, el proyecto político de los actores armados en Colombia no necesitó de una dictadura clásica para imponer esta práctica. Tercero, como política reiterada, el exilio se ha propuesto la interrupción de procesos sociales y políticos, una ruptura que afecta no sólo a quienes deben migrar forzadamente y a sus familias, sino también a los procesos sociales y colectivos en que estas personas estaban inmersos, de modo que el impacto del exilio debe medirse no sólo fuera de Colombia sino dentro de ella, a partir de estrategias que permitan cuantificar el daño que significa la desarticulación del tejido social por la privación violenta y súbita de referentes y la interrupción o sofocamiento de experiencias colectivas. Cuarto, que la agencia política del colectivo de víctimas del exilio también ha sido una característica transversal a las experiencias regionales, incluyendo la colombiana y esta agencia debe ser recuperada y reivindicada porque, aun cuando no reemplaza, sí repara en alguna medida la ruptura de procesos sociales y políticos derivada de la práctica de exilio forzado. Quinto, que estas redes creadas desde el exilio y los agenciamientos que se desarrollan en torno de ellas se articulan con luchas 
históricas por memoria, verdad y justicia en el continente, y tienen como uno de sus propósitos comunes la lucha contra la impunidad. Sexto, que el exilio mismo es un espacio de disputas sociales y políticas, que debe ser nombrado y puesto en contexto, no sólo para hacerlo visible y comprensible para la sociedad en general, sino para fortalecer la agencia de los propios exiliados, quienes muchas veces con su silencio, culpa, vergüenza u ocultamiento, son víctimas también del ocultamiento o anulación de sus propias historias de vida, de sus trayectorias sociales y políticas, aportando al gran proceso de exclusión que el exilio se propone consumar.

Es necesario entonces nombrar y poner en contexto el exilio colombiano. Este es un primer paso que posibilitará avanzar hacia diversas formas de reparación. Actualmente hay avances significativos y un gran esfuerzo en la toma de testimonios en el exterior, que no sólo abordan los hechos victimizantes vividos dentro de Colombia sino también los relacionados con el exilio en sí, como experiencia traumática y como experiencia de lucha y rearticulación de fuerzas. Esta fase ha permitido visibilizar la existencia del fenómeno, principalmente, en los países de acogida. Sin embargo, el reto que mencionamos, el de politizar el exilio, nos enfrenta aún con varios interrogantes: ¿cómo avanzar dentro de Colombia donde se niega su existencia o se percibe como una de las menores afectaciones en el marco del conflicto? ¿de qué forma quienes se quedaron, tanto como quienes se vieron forzados a partir, pueden reflexionar sobre el exilio como una forma más de la represión, como parte de la lucha por la paz y como una posibilidad más en la búsqueda de transformaciones sociales y políticas para el país?

Se trata de un gran reto para una sociedad que ha naturalizado la violencia socio-política, donde crímenes tan atroces como la desaparición forzada o las ejecuciones extrajudiciales no logran conmover lo suficiente para romper con el círculo de la impunidad. Una sociedad donde la migración forzada y no forzada, representa cerca del diez por ciento de la población colombiana y donde el fenómeno se lee no como una pérdida/afectación sino como posibilidad para la movilidad social y prosperidad, reforzado por el hecho de que las remesas ocupan un renglón importante del PIB, elemento no menor a la hora de dimensionar lo que implica vivir fuera del territorio como extranjero y peor aún en condición exilio.

Pero estos retos no son exclusivos del caso colombiano. Refiriéndose al caso argentino, Jensen (2008, p.147) sostiene que, los exiliados/as sufren un borramiento de sus identidades socio-políticas similar al buscado con la desaparición, la muerte, la privación de la libertad o la tortura, con el agravante de que son considerados/as víctimas menores:

Son estos silencios también los que se deben romper. Lograrlo depende en gran medida de la confianza generada, del cumplimiento de los compromisos, del fortalecimiento de las organizaciones de exiliados/as y de la visibilización dentro del país para avanzar hacia el reconocimiento de este hecho victimizante. 
Fortalecer y ampliar los esfuerzos por visibilizar la magnitud del exilio colombiano y sus impactos sobre los procesos colectivos-comunitarios dentro del territorio nacional posibilitará dimensionar las afectaciones que ha ocasionado al tejido social: cómo vivieron y viven el exilio familiares, amigos/ as y compañeros/as de militancias sociales y políticas que se quedaron, y de qué manera les afectó la ausencia de quienes tuvieron que partir. Buscar algunas respuestas a estos interrogantes podría allanar el camino hacia el reconocimiento y diversas formas de reparación.

Para miles de colombianos y colombianas, víctimas del conflicto armado, la Comisión de la Verdad de Colombia abrió una puerta institucional para su reconocimiento. Tal avance fue el resultado de años de movilizaciones por parte de colectivos de víctimas, tanto en Colombia como en el exterior. En este último caso, diferentes grupos ya venían organizándose en torno a reivindicaciones vinculadas tanto a su condición de exilio como de nuevos habitantes en los países de acogida. Las dificultades para visibilizar y politizar el exilio dentro de Colombia, contrastan con estas trayectorias organizativas y con la agencia política que las víctimas del exilio han sostenido a lo largo de los años. Desde la perspectiva institucional, se cuenta con experiencias previas de comisiones que tomaron testimonios de víctimas del exilio en el exterior. Por otra, existieron distintos tipo de alianzas y organizaciones de víctimas que, a través de redes de confianza, lucharon por ser reconocidos e impulsaron procesos políticos tanto en sus países de origen como de acogida en el marco de diferentes experiencias de exilio en el pasado reciente.

Sin duda alguna, la acción e incidencia transnacional en torno a la implementación del enfoque extraterritorial del SIVJRNR ${ }^{4}$ da cuenta de cómo los vínculos políticos se extienden a través de las fronteras y en el tiempo, de cómo las acciones políticas, formales e informales, se entrelazan y dan cabida a multiplicidad de lugares, procesos y prácticas, que transforman los espacios y las estructuras políticas existentes (Moraes y Cutillas, 2018, p.613).

En 2019 la CIDH promulgó dos declaraciones que es pertinente reseñar. Mediante la Resolución 3/19 aprobó los "Principios sobre Políticas Públicas de Memoria en las Américas" considerando la necesidad de desarrollar lineamientos para el diseño, elaboración e implementación de políticas públicas de memoria acordes con las obligaciones estatales de provisión de verdad, justicia, reparación y medidas de no repetición de las graves violaciones a los derechos humanos. En ese marco consideró la necesidad de promover la articulación regional para la prevención, investigación, juzgamiento y sanción de las graves violaciones a los derechos humanos ocurridas; y el

4 El Sistema Integral de Verdad, Justicia, Reparación y No Repetición fue creado por el punto 5 del Acuerdo de Paz e integra mecanismos autónomos judiciales y extrajudiciales como son: (i) la Comisión para el Esclarecimiento de la Verdad, la Convivencia y la No Repetición; (ii) la Unidad de Búsqueda para Personas dadas por Desaparecidas; (iii) la Jurisdicción Especial para la Paz; y establece medidas de reparación integral para la construcción de paz y las garantías de no repetición. 
intercambio de experiencias y buenas prácticas, tanto a nivel de los Estados como de las organizaciones de víctimas. Por otro lado, aprobó la Resolución 04/19 "Principios interamericanos sobre los derechos humanos de todas las personas migrantes, refugiadas, apátridas y víctimas de la trata de personas" con el objetivo de consolidar y profundizar directrices y lineamientos para el diseño, elaboración, implementación y evaluación de políticas públicas para la protección y promoción de los derechos de las personas migrantes, refugiados, apátridas y en situación de desplazamiento y movilidad. Resulta relevante celebrar ambas iniciativas, así como llamar la atención sobre la ausencia de un reconocimiento explícito del derecho a la memoria, la verdad y la justicia de las personas con necesidades especiales de protección internacional.

El reconocimiento de las experiencias de exilio como una violación de derechos humanos no depende sólo de las víctimas y de los colectivos que las reúnen sino que requiere la asunción de responsabilidades institucionales de diferente nivel, y se inscribe en cuadros de significación nacionales y/o regionales, o internacionales, en donde ese reconocimiento adquiere sentidos específicos.

La experiencia colombiana sobre esclarecimiento de la verdad en el caso del exilio, puede aportar insumos interesantes para poner sobre la mesa a nivel regional y global la discusión acerca de la necesidad de mecanismos que garanticen el derecho a la memoria, la verdad y la justicia de las poblaciones con necesidades de protección internacional.

\section{Referencias bibliográficas}

Beristain, C. (2018). Voces desde el exilio. La Verdad sobre la violencia en Colombia, Revista Haroldo. 14 de diciembre de 2019. Recuperado de: https://revistaharoldo.com.ar/index. php

(SF). Reconstruirse desde las cenizas: La comisión de la verdad y los exilios de Colombia, Lasa Forum 51:1 30

CNMH. Centro Nacional de Memoria Histórica. (2018). Exilio colombiano. Huellas del conflicto armado más allá de las fronteras. Bogotá: $\mathrm{CNMH}$.

Ema, J. E., (2004). Del sujeto a la agencia (a través de lo político), Universidad Autónoma de Barcelona, Rev. Athenea Digital, núm. 6: 1-24.

Jensen, S. (2017). Los exiliados argentinos y las luchas por la justicia (1976-1981), Estudios 38: 13-30.

(2008). ¿Por qué sigue siendo políticamente incorrecto hablar de exilio? La dificultosa inscripción del exilio en las memorias sobre el pasado reciente argentino (1983-2007), Revista digital de la Escuela de Historia 1(- unr / año 1 - n 1) 129 / Rosario, Argentina, 131-148.

Lima. A. (2020). 40 años del exilio guatemalteco. Comunicado de prensa, 5/03/2020. Recuperado de: https://www.acnur.org/es-mx/noticias/press/2020/3/5e6170034/40-anos-d el-exilio-guatemalteco.html 
Ludec, N. (2001). Voces del exilio guatemalteco desde la ciudad de México, Amérique Latine Histoire et Mémoire. Les Cahiers ALHIM 2. Recuperado de: http://journals.openedition. org/alhim/599.

Moraes, N.\& Cutillas, I. (1998). La estructura de oportunidad política transnacional y el giro relacional en el análisis de la participación política y el asociacionismo migrante.Revista de psicología, Universidad de Murcia, 605-624

Ortíz, Diana. (2020). Proyecto de Tesis de doctoral. Participación política transnacional en la lucha por la memoria, la verdad y la justicia. La experiencia del exilio colombiano en Argentina: diálogos de paz e implementación del Sistema Integral de Verdad, Justicia, Reparación y No Repetición derivado de los acuerdos de paz (2012-2019). Instituto de Desarrollo Económico y Social IDES/UNGS, Buenos Aires, Argentina.

Ortiz, D. \& Viloria, M. (2018). Aportes para la implementación del enfoque extraterritorial de la Comisión para el Esclarecimiento de la Verdad, la Convivencia y la No Repetición. MECoPa

Pollak, M. (2006). Olvido, memoria y silencio. La producción social de identidades frente a situaciones límite: Ediciones al margen, Buenos Aires, Argentina

Silber, I. (2012). “¿Aguantar hambre o luchar?”. Una perspectiva antropológica de la postguerra, Identidades 4/II: 127-146.

Sprenkles, R. (2012). La guerra como controversia: una reflexión sobre las secuelas políticas del informe de la Comisión de la Verdad para el Salvador, Identidades 4/II: 68-89.

Valencia, R. (2016). Las maras se arman con fusiles de la guerra civil, 7/o9/2016. https://elfaro. net/es/2016og/salanegra/19208/Las-maras-se-arman-con-fusiles-de-la-guerra-civil.htm

Zúñiga, M. (2010). Heridas en la memoria: la guerra civil salvadoreña en el recuerdo de niñez de un pandillero, Historia Crítica, (40), 60-83. 